\title{
Late Revascularization on Upper Extremity: Case Series
}

\author{
Salazar Vizuet Israel ${ }^{1 *}$, Del Villar Trujillo Andrea ${ }^{2}$, Kist Aguilar Christian ${ }^{3}$, Romero Espinosa \\ Jesús Fernando ${ }^{4}$, Orozco Gómez José Antonio ${ }^{5}$, Robles Méndez Hernández Alberto ${ }^{6}$ \\ ${ }^{1}$ Medical Staff Plastic and Reconstructive Surgery Department, Medical Center Lic. Adolfo Lopez Mateos, \\ Mexico \\ ${ }^{2}$ Medical Resident PGY-4 Plastic and Reconstructive Surgery Department, Medical Center Lic. Adolfo Lopez \\ Mateos, Mexico \\ ${ }^{3}$ Medical Resident PGY-2 Plastic and Reconstructive Surgery Department, Medical Center Lic. Adolfo Lopez \\ Mateos, Mexico \\ ${ }^{4}$ Chief of Staff Plastic and Reconstructive Surgery Department, Medical Center Lic. Adolfo Lopez Mateos, \\ Mexico \\ ${ }^{5}$ Medical Resident PGY-1 Plastic and Reconstructive Surgery Department, Medical Center Lic. Adolfo Lopez \\ Mateos, Mexico \\ ${ }^{6}$ GeneralSurgeryDepartment, Hospital Angeles Metropolitano, Mexico
}

*Corresponding Author: Dr. Israel Salazar Vizuet, Medical Staff Plastic and Reconstructive Surgery Department, Medical Center Lic. Adolfo Lopez Mateos, Mexico.

\section{Summary}

Upper limb injuries correspond to $29.25 \%$ of the admitted cases in the emergency room in our Institution, after head and neck injuries. Upper limb physiological amputation needs to be done after 6 to 8 hours after the secondary injury due to high risk of complication such as reperfusion syndrome and compartmental syndrome.

In this article, we report three cases of delay revascularization. On which more than 10 hours pass after secondary injury, in two of our three cases satisfactory revascularization was performed associated with prophylactic fasciotomies, the other patient had to be amputated due to reperfusion syndrome.

Collateral circulation influences in the preservation of distal irrigation, it can maintain the perfusion of an extremity, allowing to perform late revascularization with favorable outcome, prophylactic fasciotomies can diminish the risk of compartment syndrome, although with high risk of reperfusion syndrome.

Keywords: vascular injury, vein graft, compartment syndrome, reperfusion syndrome

\section{INTRODUCTION}

Upper Limb Injuries are the second cause of admission to the emergency room at the "Lic. Adolfo López Mateos " second level hospital, with $29.25 \%$, in first place are head and neck injuries with $33 \%$ and in third place injuries of the lower limb in $15.87 \%$.[1] The trauma mechanism are mainly crashing, gunshot and knife injury, among others.

Ischemia is defined as a decrease in perfusion causing limb compromise. Ischemia can be classified into acute and chronic. Acute ischemia is the sudden lack of blood supply, due to intrinsic factors (thrombus occlusion) or extrinsic factors such as compartmental syndrome or an occlusion and / or direct section on the blood vessel. Chronic ischemia is the gradual decrease in diameter secondary to diseases such as atherosclerosis, autoimmune or other causes.[2]

The blood supply to the upper limb begins with the brachial artery, the brachial artery and its branches are the main blood supply to the arm, starting bellow the teres major muscle and ending at the elbow level with the bifurcation of the radial artery and the ulnar artery. The brachial artery runs along the medial surface of the arm giving direct cutaneous branches, and ulnar collateral branches (superior and inferior) ending at the level of the recurrent anterior 
(superior) and posterior (inferior) ulnar artery at the elbow joint.

The deep brachial artery is a branch of the brachial artery, it runs along with the radial nerve. It emits branches including the nutritive artery of the humerus, medial collateral branch and collateral radial branch. The middle collateral branch goes to the recurrent posterior interosseous artery. The radial collateral artery turns until it reaches the recurrent radial artery, which is a branch of the radial artery.[3] (Figure 1)

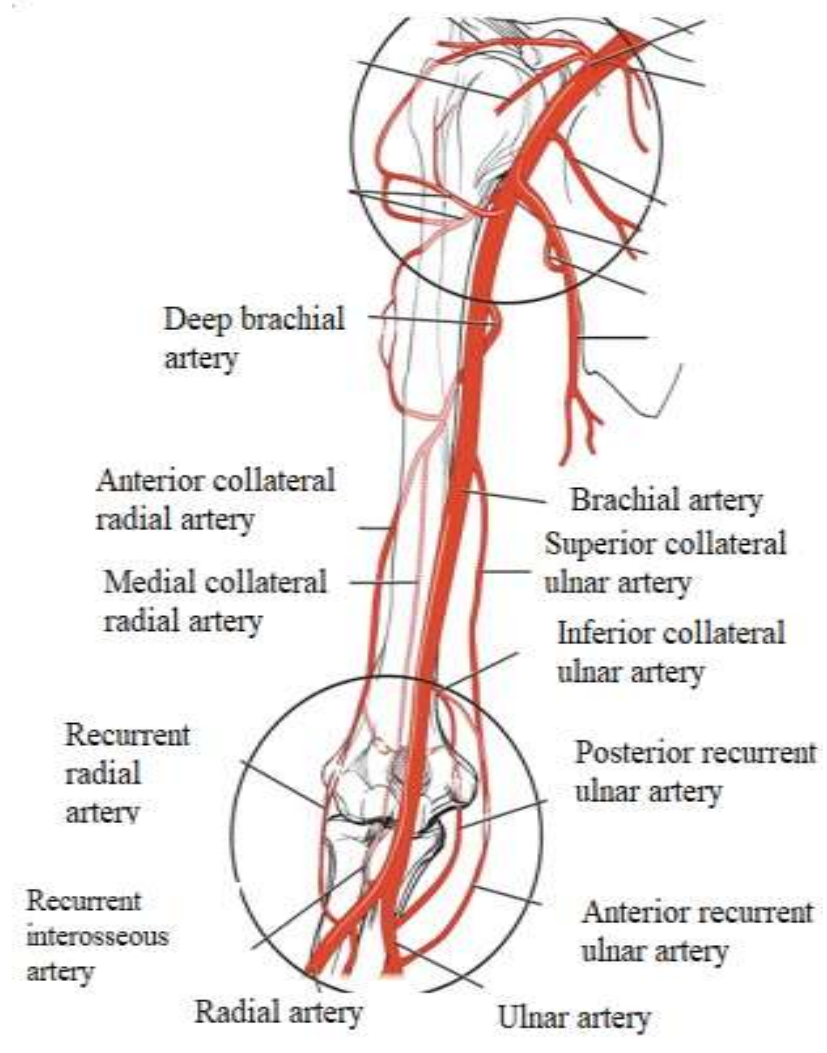

Figure1. Vascular Anatomy

Prucz et al. described that to be able to perform an upper limb reimplantation at the level of the arm and forearm it takes approximately 6 to 8 hours in cold ischemia and 2 to 4 hours in warm ischemia.[4]The muscle tends to suffer and releases free radicals, activation of proteases and phospholipase that leads to an inflammatory process activating platelet factors and the metabolites that generate reperfusion syndrome causing the need of amputation even death.

Preserving the limb decisions may be borderline, misinterpretation of scales can be part in the process, it depends on multiple factors that include: the mechanism of injury, level of amputation, ischemia time, patient age, occupation, and comorbidities.[5] There are multiple scales such as: Mangled Upper Extremity Score (MUES) and Mangled Extremity Severity Score (MESS).The MESS scale is the most used to save the lower limb, however it has not been validated for the upper limb, leading to multiple errors to preserve the limb when it is unlikely to obtain a satisfactory result.[6]

\section{Compartment Syndrome}

Compartment syndrome is defined as a pressure above the capillary perfusion pressure (> 30 $\mathrm{mmHg}$ ) within a closed compartment, which presents a compromise in blood flow in muscle and nerve, causing tissue damage. Multiple etiologies can result in compartment syndrome from external compression secondary to bandaging, burns, prolonged use of a tourniquet, up to intrinsic compression due to edema, vascular injury, coagulation alterations, fractures, among others. Fasciotomies were first performed by Norman Rich in World War II 1940, for battlefield injuries. The use of prophylactic fasciotomies is controversial, however, there are surgeons who use it to reduce 
late sequelae. The indications for these are: ischemia greater than 6 hours, massive venous thrombosis, complex limb fractures, crushing trauma, limb reimplantation, edema, sensory or motor deficit.[7]

The arm has two compartments: anterior and posterior. In the anterior compartment is the bicipital, brachialis and coracobrachialis muscles, at a posterior level it is the triceps and anconeus. The brachial artery runs in the bicipital canal, where it is accompanied by two veins and the median nerve.

The forearm has 3 compartments: volar or anterior, dorsal or posterior, and lateral. The volar compartment is divided into two: superficial (pronator teres, palmaris longus, flexor carpi radialis, flexor carpi ulnaris, superficial flexor of the fingers) and deep compartment (deep flexor of the fingers, long

Table1. Hard and soft signs flexor of the thumb, and pronator quadratus). The dorsal compartmentis divided in superficial (extensor digitiminimi, extensor digitiminimi di fifth finger, extensor carpi ulnaris ulnar) and deep (extensor pollicis brevis, abductor pollicis longus, extensor pollicis longus, extensor proper of the index and short supinator).The lateral compartment (Extensor radialis brevis, extensor radialis longus, and brachioradialis).

When an anterior fasciotomy is performed, it can decompress the dorsal and lateral compartments. The best approach has been studied when performing a radial, central, or ulnar fasciotomy. It was observed that ulnar fasciotomy presents less morbidity, being able to free up the space better. The comprehensive evaluation of the patient first explores hard signs and soft signs (Table 1).[8]

\begin{tabular}{|l|l|}
\hline \multirow{4}{*}{ Hard signs } & Active hemorrhage \\
\cline { 2 - 2 } & Absent distal pulses or ischemia \\
\cline { 2 - 2 } Soft signs & Expandingorpulsatile hematoma \\
\hline & Bruitorthrill \\
\hline Salas 2011 & Subjective reduced or unequal pulses \\
\cline { 2 - 2 } & Large non-pulsatile hematoma \\
\cline { 2 - 2 } & Orthopedic injuries carrying a high index of suspicion of vascular injury \\
\cline { 2 - 2 } & Neural injury \\
\hline
\end{tabular}

The hard signs tell us of urgent surgery at that time. With soft signs, it can be suspected but we need to perform Doppler ultrasound, if it is not satisfactory, perform angiography and assess surgical vs. conservative treatment.[9]It should be remembered that the upper limb should always be saved even when it may present sequelae such as poor sensitivity and movement, rather than the use of prostheses.[10]

\section{CASE}

\subsection{Clinical Case 1}

64-year-old male patient, who presented a lesion on the antero-medial surface of the right arm, (Figure 2) referred to our hospital 26 hours after the trauma. A lesion is found on the anteromedial surface of the right arm with a section of the neurovascular bundle of the bicipital canal, with absent radial and ulnar pulses on palpation with paleness on exploration. Audible Doppler was placed detecting pulses, finding arterial flow data in both arteries, so it was decided to perform the vascular exploration.

In the operating room, a complete section of the brachial artery was found, with retrograde flow of the brachial artery (adequate passage of collateral and recurrent arteries), so it was decided to take an $8-\mathrm{cm}$ reverse cephalic vein vascular graft (Figure 3) and anastomosis is performed. Subsequently, a prophylactic fasciotomy is performed, releasing both its superficial and deep portions of the anterior compartment. A bandage is applied, it is managed with heparin (low molecular weight) postoperatively, analgesics and parenteral solutions. Seven days later, skin grafts are placed in the bloody area of the anterior fasciotomies for skin covering (Figure 4). 


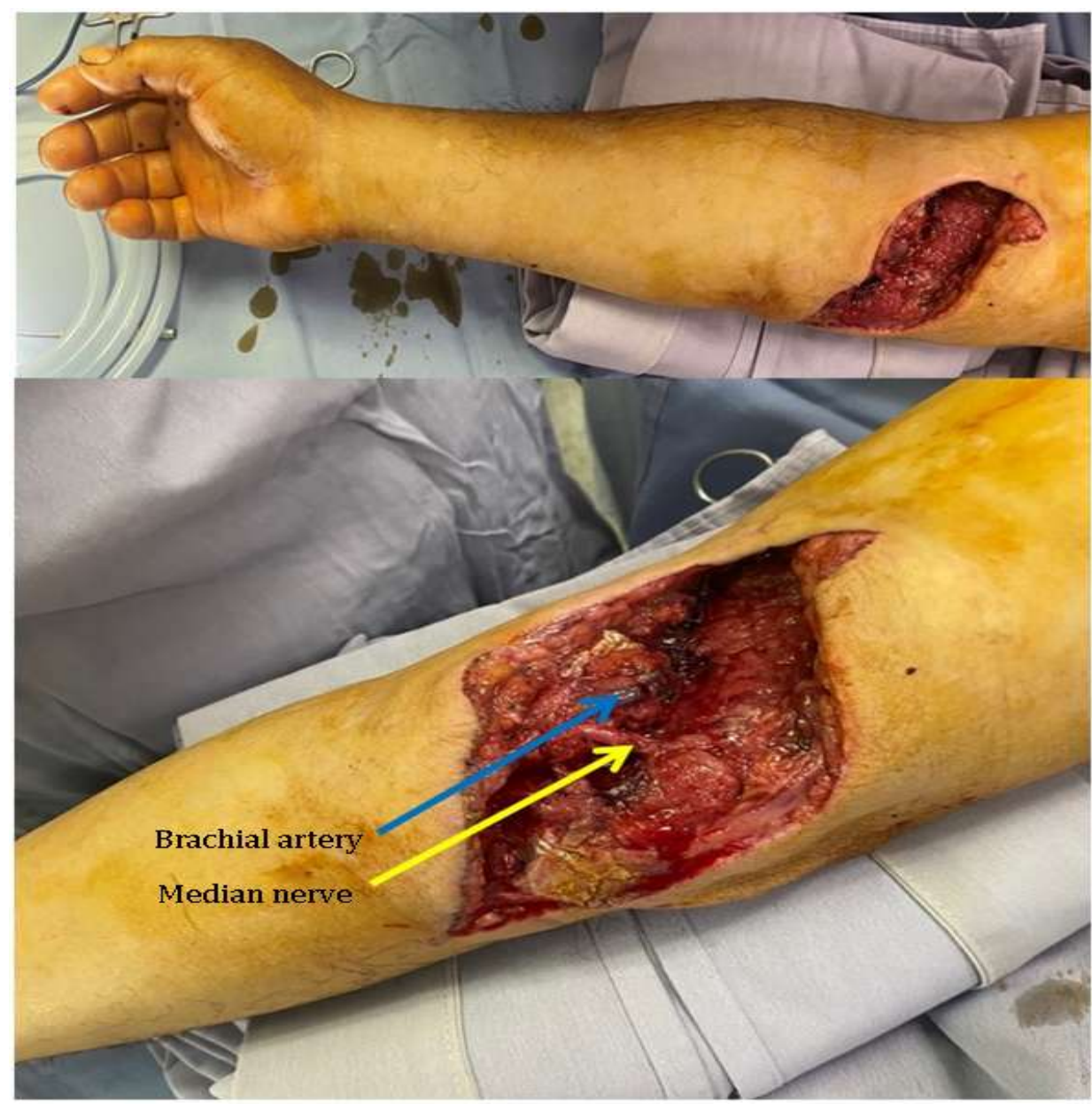

Figure2. Injury at the level of the elbow fold with section of the brachial biceps, brachial artery (blue arrow) and median nerve (yellow arrow)

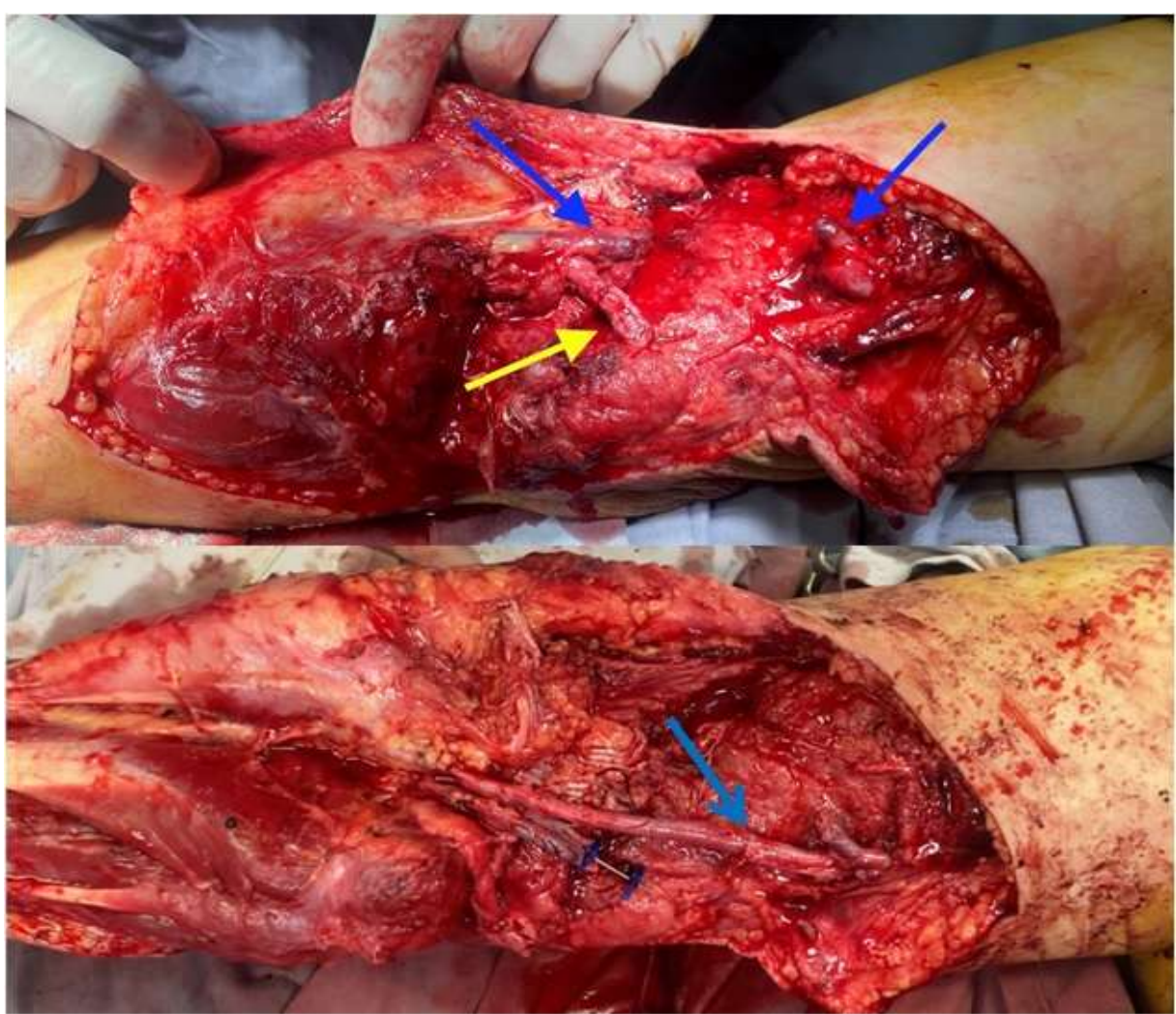

Figure3. Brachial artery anastomosis with $8 \mathrm{~cm}$ long reverse venous graft of the cephalic vein 


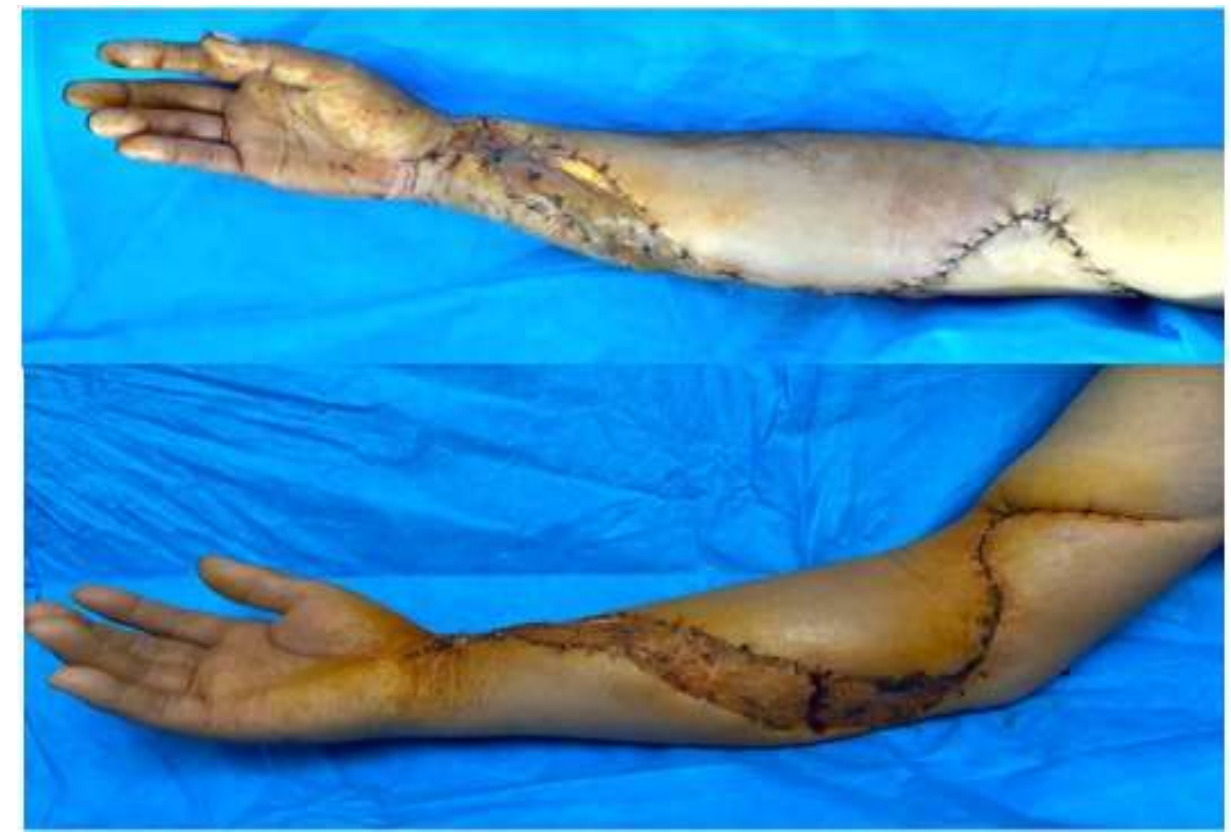

Figure 4. Postoperative photograph at 7 days, with adequate integration of the grafts, with proximal primary closure

\subsection{Clinical Case 2}

53-year-old male patient with a rollover injury to the right forearm (Figure 5) with delivery at 11 am after the injury, with an 11-point MESS scale. No palpable pulses but it was decided to explore the forearm to assess revascularization. At the time of surgical exploration, retrograde flow of the brachial artery was observed, secondary to the patency of the recurrent and collateral arteries, for which an anastomosis of the brachial artery with a cephalic vein graft was performed. However, he presented bullae on the back of the arm (Figure 6). Because of elevation of creatinine phosphokinase (CPK) up to 22,000 and lack of muscle contraction under direct stimulation in all compartments it was decided to limb amputation.

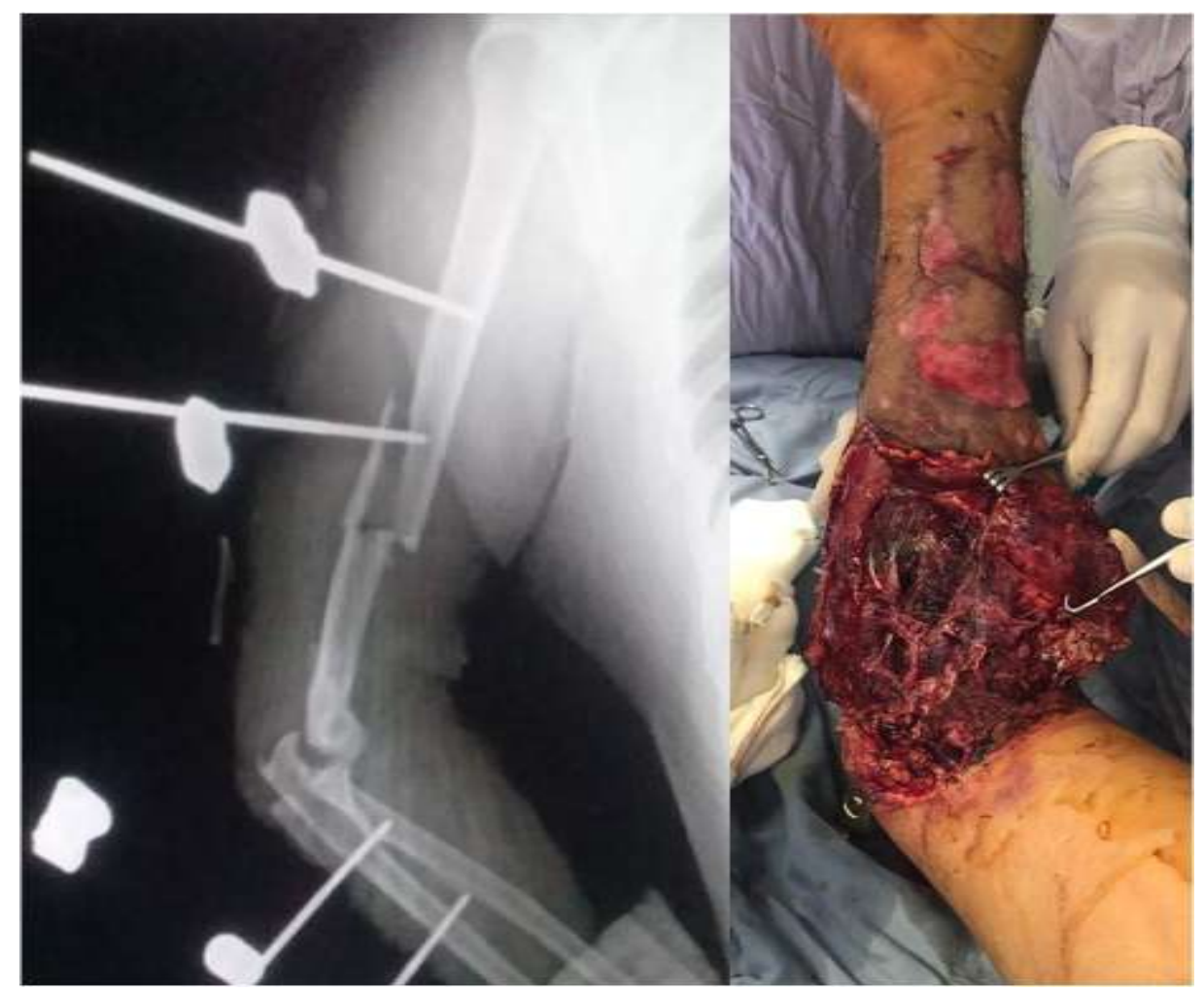

Figure5. Injury on the anteromedial surface of the arm and forearm with humerus fracture 


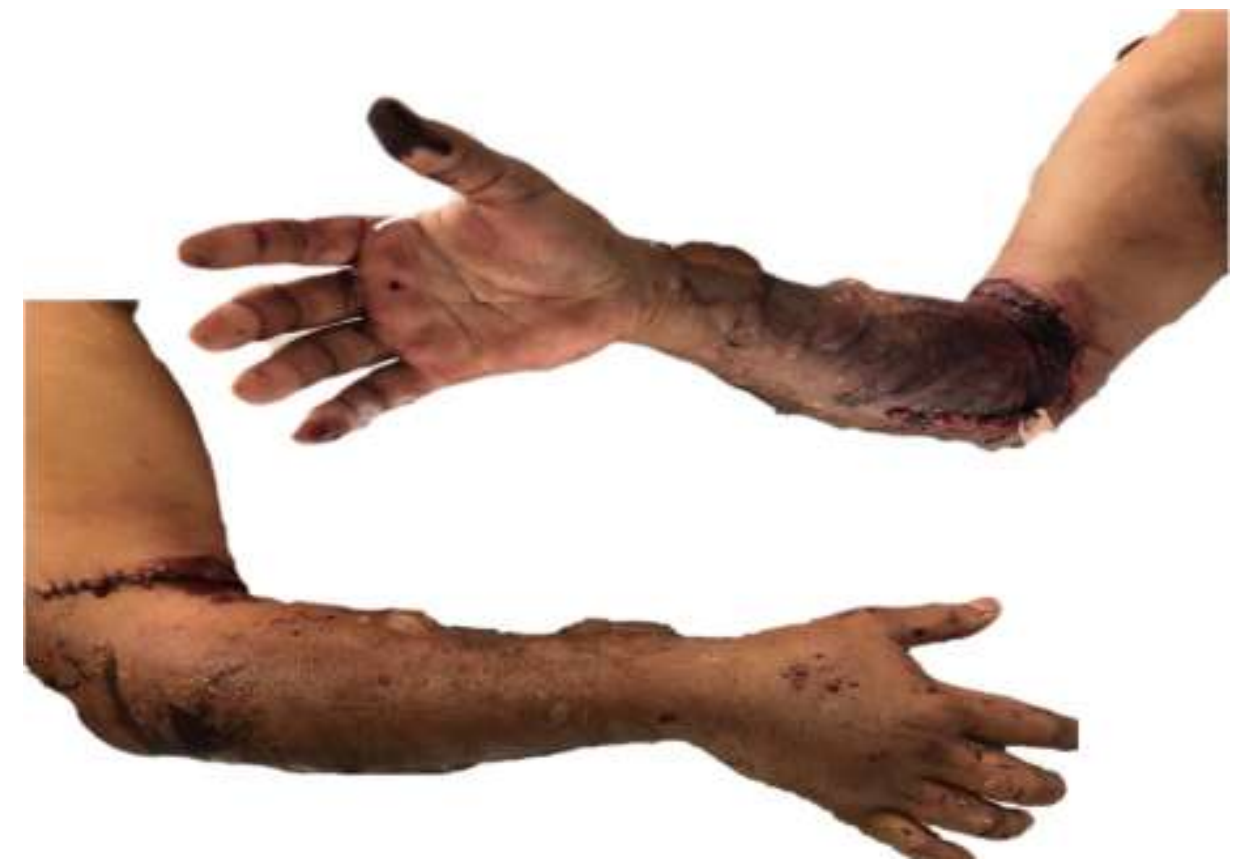

Figure6. Ampoules are observed at the level of the arm and forearm, fasciotomies were not performed in this case

\subsection{Clinical Case 3}

43-year-old male patient with avulsion of the anteromedial surface of the arm with loss of the right brachial neurovascular bundle, loss of the axillary and anterior cutaneous surface of the right shoulder (Figure 7), sent to our unit on the third day to assess surgical treatment The absence of a $15 \mathrm{~cm}$ segment of the brachial artery is observed, taking a saphenous vein graft from the left leg, taking a sural nerve graft for the posterior interosseous nerve (Figure 8); latissimus dorsi muscle flap (figure 9) to cover the bloody area, a prophylactic fasciotomy was performed on the forearm with application of a skin graft.

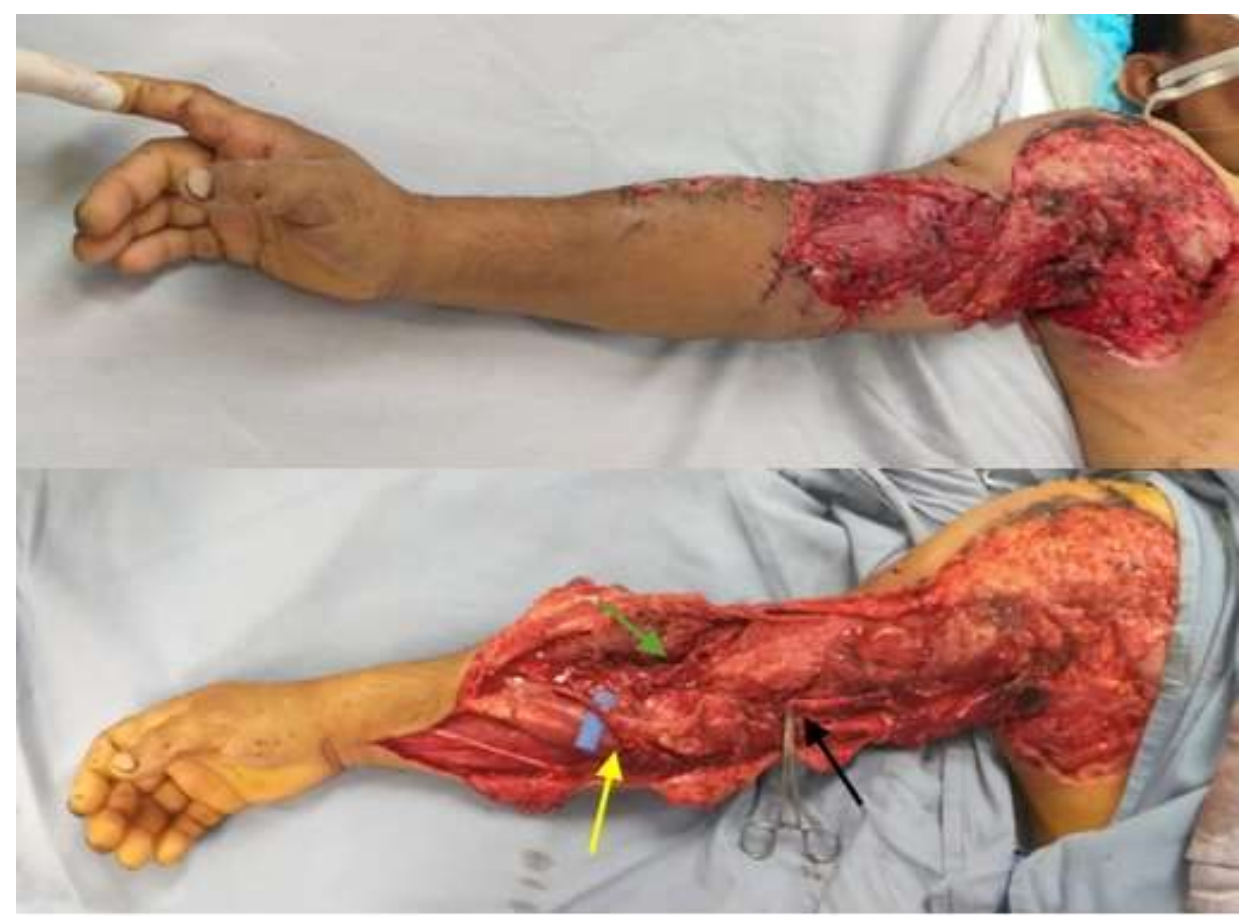

Figure 8. a) Upper: saphenous vein graft; lower: sural nerve graft. b) Anastomosis of the saphenous vein with the brachial artery at its distal and proximal end. c) Adequate venous graft perfusion. d) Sural nerve graft for the posterior interosseous nerve (green arrow). Vein graft coverage (black arrow) is observed by the latissimus dorsi muscle flap (blue arrow). 


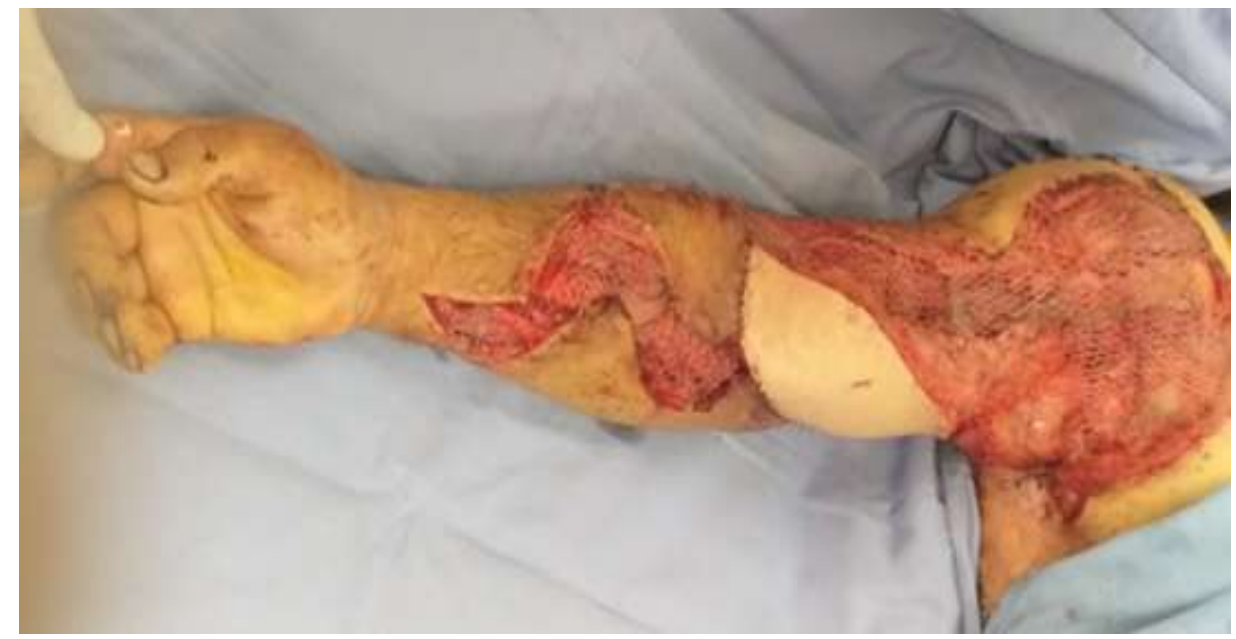

Figure9. Result. Latissimus dorsi musculocutaneous flap with cutaneous cover for anastomosis, collection, and application of intermediate partial thickness skin graft to cover the fasciotomy and bloody area

\section{DISCUSSION}

Vascular injury treatment is a complicated and challenging decision. Mahajan et al [11] described that it is always easier to perform an amputation, it will have lower cost and less hospital stay, but saving the limb psychologically is more accepted, the purposes in our case series was far as possible to preserve the limb.

Brachial artery injuries on multiple occasions make us think of a physiological amputation or critical arterial injury of the forearm, requiring immediate revascularization, and otherwise, if it is after the recommended 6 hours, amputation is suggested, as published by Lance.[12]

However, the knowledge of the anatomy and the clinical evidence of the integrity of the circulation of the arm, still allows a flow of blood through it, so it can increase the revascularization period as in the case of two patients. The clinical data on which we rely to perform revascularization was the hard and soft signs published by Salas [9], the viability of the limb using Doppler at the level of the distal radial and ulnar artery and muscle functionality as described by Mahajan.[11] We never base an amputation or revascularization decision on pin prick test (fine bleeding in the distal puncture), since the distal limb may have distal bleeding, however, if there is no muscle contractility it means no muscle viability.

The upper limb that suffers the abrupt or partial interruption of the arterial line leads to inflammation and edema, among other factors published by Merle.[13]When a limb is revascularized in less than 6 hours it causes mild edema, but when injury greater than 6 hours implies greater edema and inflammation, it is necessary to perform prophylactic fasciotomy on a mandatory basis to avoid greater muscle ischemia and improve the forecast regarding feasibility and functionality.

The main goal is to maintain a limb regardless the degree of functional recovery.[14] However, this perspective has changed, as the importance of preserving a limb is maintaining its functionality. Arm prostheses are more expensive and less effective than pelvic limb prostheses.[5] Despite the surgical time, complying with the clinical data, to save the limb, it should put on top of our options, and help the functionality of the limb through rehabilitation in the aftercare for a successful revascularization to be considered. However, in some cases subsequent surgeries will be necessary to be able to adequately restore function, which may include tendon and nerve repairs, free flap muscle transfer, treatment of chronic wounds or to improve ranges of motion, among other sequelae.[15] The incidence of secondary procedures after limb revascularization or reimplantation is reported from $15 \%$ to $80 \%$ with an average of $50 \%$ of cases.[16] If it is decided to perform the amputation due to lack of viability or a prolonged time without muscle function, together with all the signs of poor prognosis, they should not be taken as a failure in a surgical procedure, but rather a way to achieve greater functionality for the patient. coinciding with the thought of Savestky who proposes a long-term functionality scale to discern in this decision.[6]

\section{Conclusions}

We consider that any upper limb lesion associated with brachial artery injury with 
collaterals vascular supply preservation, warrants surgical exploration and attempts a revascularization even if it is outside the suggested window hours. It is possible to revascularize the limb and obtain good functional results, carrying out the necessary prophylactic measures to avoid compartment syndrome. Any critical arterial injury of more than 6 hours of evolution with the presence of clinical data, audible distal arterial pulse by Doppler, reverse flow distal to the injury, muscle function should be revascularized, as well as prophylactic fasciotomy to increase the probability of success.

\section{REFERENCES}

[1] Consuelo-Estrada JR, Gaona-Valle LS, Portillo-Rodríguez O. Lesiones por causa externa en el servicio de urgencias de un hospital en un periodo de cinco años. Gac Mexico. 2018 May 4;154(3):585.

[2] McNally MM, Univers J. Acute Limb Ischemia. Surg Clin North Am. 2018 Oct;98(5):1081-96.

[3] Morris SF, Tang M, Almutari K, Geddes C, Yang D. The Anatomic Basis of Perforator Flaps. Clin Plast Surg. 2010 Oct;37(4):553-70.

[4] Prucz RB, Friedrich JB. Upper Extremity Replantation: Current Concepts. Plast Reconstr Surg. 2014 Feb;133(2):333-42.

[5] Chinta MS, Wilkens SC, Vlot MA, Chen NC, Eberlin KR. Secondary Surgery following Initial Replantation/Revascularization or Completion Amputation in the Hand or Digits: Plast Reconstr Surg. 2018 Sep;142(3):709-16.

[6] Savetsky IL, Aschen SZ, Salibian AA, Howard $\mathrm{K}$, Lee Z-H, Frangos SG, et al. A Novel Mangled Upper Extremity Injury Assessment Score: Plast Reconstr Surg - Glob Open. 2019 Sep;7(9):e2449.

[7] Mendoza CA, Manzo CHA. Síndrome compartimental en extremidades. Conceptos actuales. Cir Gen. 2003;25(4):342-348.

[8] Ronel DN, Mtui E, Nolan WB. Forearm Compartment Syndrome: Anatomical Analysis of Surgical Approaches to the Deep Space: Plast Reconstr Surg. 2004 Sep;114(3):697-705.

[9] Cristián Salas D. Trauma vascular, visión del cirujano vascular. Rev Médica Clínica Las Condes. 2011 Sep;22(5):686-95.

[10] Ekim H, Tuncer M. Management of traumatic brachial artery injuries: A report on 49 patients. Ann Saudi Med. 2009 Mar;29(2):105-9.

[11] Mahajan G, Kotru M, Sharma R, Sharma S. Usefulness of Histopathological Examination in Nontraumatic Perforation of Small Intestine. J Gastrointest Surg. 2011 Oct;15(10):1837-41.

[12] Lance RH. Limb Reconstruction Versus Amputation Decision Making in Massive Lower Extremity Trauma, Clinical Orthopaedics and Related Research: June 1989 - Volume 243 - Issue - p 92-99.

[13] Merle G, Harvey EJ. Pathophysiology of Compartment Syndrome. In: Mauffrey C, Hak DJ, Martin III MP, editors. Compartment Syndrome [Internet]. Cham: Springer International Publishing; 2019 [cited 2021 Jan 4]. p. 17-24. Available from: http://link.springer.com/10.1007/978-3-03022331-1_3

[14] Khan N, Rashid M, ur Rashid H, Ur Rehman Sarwar S, Khalid Choudry U, Khurshid M. Functional Outcomes of Secondary Procedures in Upper Extremity Replantation and Revascularization. Cureus [Internet]. $2019 \mathrm{Jul}$ 17 [cited 2021 Jan 4]; Available from: https://www.cureus.com/articles/21367functional-outcomesof-secondary-proceduresin-upper-extremity-replantation-andrevascularization

[15] Yu J-C, Shieh S-J, Lee J-W, Hsu H-Y, Chiu HY. Secondary procedures following digital replantation and revascularisation. $\mathrm{Br} \mathrm{J}$ Plast Surg. 2003 Mar;56(2):125-8.

[16] Frey M, Mandl H, Holle J. Secondary operations after replantations. Chir Plast [Internet]. 1980 [cited 2021 Jan 4];5(4). Available from: http://link.springer.com/ 10.1007/BF00263373

Citation: Salazar Vizuet Israel, Del Villar Trujillo Andrea, Kist Aguilar Christian, Romero Espinosa Jesús Fernando, Orozco Gómez José Antonio, Robles Méndez Hernández Alberto. "Late Revascularization on Upper Extremity: Case Series". ARC Journal of Surgery. 2021; 7(1):1-8. DOI:https://doi.org/10.20431/2455$572 X .0701001$.

Copyright: (ㅇ 2021 Authors. This is an open-access article distributed under the terms of the Creative Commons Attribution License, which permits unrestricted use, distribution, and reproduction in any medium, provided the original author and source are credited. 